(c) 2013 Plant Management Network.

Accepted for publication 6 November 2013. Published 25 November 2013.

\title{
The 12th I. E. Melhus Graduate Student Symposium: Host Plant Resistance and Disease Management, Current Status, and Future Outlook
}

\author{
C. S. Kousik, U.S. Vegetable Laboratory, USDA-ARS, 2700 Savannah \\ Highway, Charleston, SC 29414 \\ Corresponding author: C. S. Kousik. shaker.kousik@ars.usda.gov
}

Kousik, C. S. 2013. The 12th I. E. Melhus graduate student symposium: Host plant resistance and disease management, current status, and future outlook. Online. Plant Health Progress doi:10.1094/PHP-2013-1125-01-PS.

The 12th I. E. Melhus Graduate Student Symposium was held on 6 August 2012 during the annual meeting of the American Phytopathological Society (APS) in Providence, RI. The theme for this symposium was "Host Plant Resistance and Disease Management: Current Status and Future Outlook." The APS Host Resistance Committee, in conjunction with financial support from the APS Foundation, sponsored the 12th I. E. Melhus Graduate Student Symposium. The symposium featured four graduate student presentations highlighting research that leads to a better understanding of host plant resistance, resistance breeding, and disease management. Each presenter received a travel award of $\$ 500$. The symposium was organized by Shaker Kousik, Pradeep Kachroo, Patrick Wechter, and Alemu Mengistu.

The I.E. Melhus symposium has been held annually since 1999 and is one of the most prestigious APS annual meeting events. The four featured graduate students were chosen on a competitive basis to present their thesis research results. The selection criteria for this symposium was similar to previous years and included: (i) submission of a five-page (excluding tables and figures) synopsis of the student's graduate research project; (ii) two letters of nomination from the applicants institution, one of which was submitted by the applicant's major professor. The letters had to evaluate the applicant's research and ability to present it a clear and effective manner; (iii) active membership in APS; (iv) current enrollment as a graduate student or completion of their graduate program within 12 months of the 2012 APS Annual Meeting; and (v) evaluation by an expert panel ranking the originality and significance of each applicants research towards improving our understanding of host resistance and IPM strategies. The special symposium theme was chosen by the organizers primarily because the field of host resistance is at the core of the plant pathology profession and host resistance is a key component of most integrated pest management (IPM) strategies. The increased understanding and basic knowledge of the mechanisms that contribute to host resistance have and will continue to result in better disease management strategies yielding healthier crops and increasing global food production.

The organizers of the 12th I. E. Melhus Graduate Student Symposium wish to extend special thanks to the four APS members of the Host Resistance committee who served as the judges to select the 2012 symposium awardees. The four judges were Dennis Halterman, Patrick Wechter, Alemu Mengistu, and Shaker Kousik. Special thanks are extended to Raymond Martyn who represented the APS foundation and served as the fifth judge. 


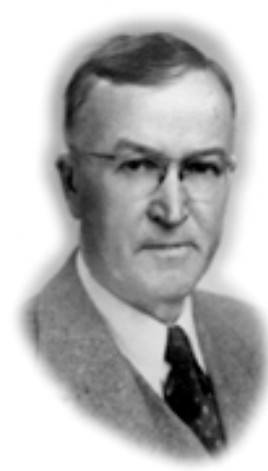

Dr. Irving E. Melhus was a renowned teacher, an innovative researcher, and an outstanding departmental administrator at Iowa State University. His breadth of experience, contributions to the practical application of disease control, classic work on root pathogens of Iowa crops, and visionary work on corn improvement epitomize a truly pioneering plant pathologist. In 1939, he coauthored the well-written textbook The Elements of Plant Pathology with Dr. G. C. Kent. His service to The American Phytopathological Society (APS) further exemplified his leadership and commitment to the profession of phytopathology. He was president of APS in 1926 and was elected a fellow of APS in 1965. Additionally, he was a member of the Iowa Academy of Sciences, the Botanical Society of America, and a fellow of the American Association for the Advancement of Science. Dr. Melhus was not only an outstanding plant pathologist; he was an inspiring mentor and an engaging personality with a keen sense of humor.

\section{The I. E. Melhus Student Symposium Fund}

The I. E. Melhus Student Symposium Fund was established through generous donations by Dr. and Mrs. William C. Paddock, Mr. and Mrs. Walter Goeppinger, and Dr. and Mrs. Jack R. Wallin to the APS Foundation. The Melhus Fund will enhance graduate student professionalism and memorialize an influential plant pathologist. A brief history of the establishment of the I.E. Melhus Student Symposium fund has been provided by Forest Nutter (doi:10.1094/PHP-2012-0723-01-PS).

\section{2th I. E. Melhus Graduate Student Symposium Participants}

The expert panel of judges received nine applications from highly qualified graduate students and had a tough task selecting the four individuals who received the 2012 Melhus award. The APS Host Resistance committee and the APS foundation congratulate the following graduate students chosen by the five judges to participate in the 12th I. E. Melhus Graduate Student Symposium. A brief introduction to each participant's research area and biography is presented below.

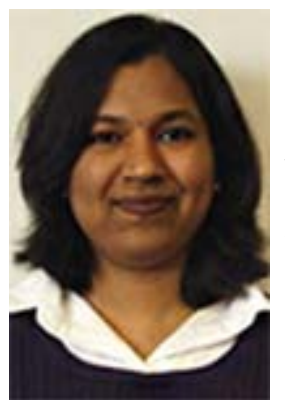

Mala Ganiger is currently a Ph.D. student with Zhi-Yuan Chen in the Department of Plant Pathology and Crop Physiology at Louisiana State University. Her research focuses on the proteomics-based study of host-fungus interactions between soybean and Phakopsora pachyrhizi. She screened several soybean recombinant inbred line (RIL)-derived sister lines for response to $P$. pachyrhizi infection using both detached leaf assay and greenhouse inoculations. She has identified several soybean and fungal proteins induced during compatible and incompatible interactions using a comparative proteomics approach. From this research, she hopes to find some "novel genes" involved in host defense against $P$. pachyrhizi that can be used to develop rust-resistant soybeans in the future.

Jonathan M. Jacobs recently finished his Ph.D. in Plant Pathology at the University of Wisconsin-Madison under the direction of Caitilyn Allen. He received a B.S. degree from the University of Wisconsin-Madison as a triple major in bacteriology, genetics, and Spanish. His thesis investigations focused on characterizing bacterial wilt disease, caused by Ralstonia solanacearum. $R$. solanacearum is considered the most destructive bacterial plant pathogen due to its broad host range, aggressiveness, and worldwide distribution. His early thesis research revealed pathogen physiological traits that are differentially

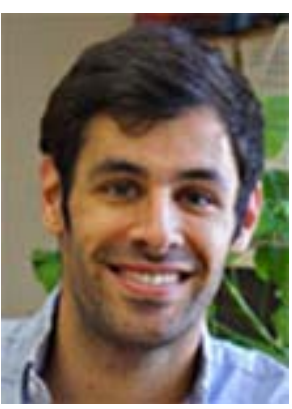
important for virulence on susceptible and resistant tomato lines. His work 
further defined the plant defense pathways targeted by the important pathogen effector PopS, which is widely conserved across plant pathogenic bacteria with Type III secretion systems. He was recently awarded a National Science

Foundation Postdoctoral Research Fellowship in Biology to conduct research on Xanthomonas-rice interactions under the direction of Sébastien Cunnac at IRD (Institut de recherche pour le développement) in Montpellier, France.

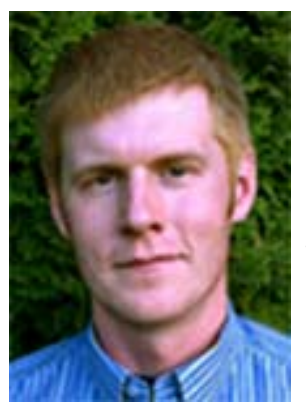

Timothy Miles recently completed his Ph.D. from Michigan State University under the direction of Annemiek Schilder. He received a B.S. degree in biology and chemistry at Western Michigan University in Kalamazoo in 2005. He started at Michigan State University in the Small Fruit Pathology Program as a master's student and then switched to the Ph.D. program. His research focused primarily on understanding blueberry anthracnose fruit rot resistance, developing new strategies to screen for resistance, and understanding the environmental factors that affect fruit infection. He identified several differentially expressed genes in a resistant cultivar following infection and linked several chemical factors to resistance. He also developed three-dimensional models to predict infection risk in immature and mature fruit under a variety of environmental conditions, such as changes in temperature, relative humidity, and interrupted and continuous wetness. After graduating, he became a postdoctoral research associate at the University of Idaho's Aberdeen Research and Extension Center working with Phillip Wharton on potato diseases. This work included characterizing fungicide resistance in Alternaria solani populations, surveying Rhizoctonia populations for different anastomosis groups on potatoes, and looking at fungicide efficacy on a variety of potato diseases. During his appointment he identified novel mutations in succinate dehydrogenase-resistant isolates of $A$. solani and found a variety of different anastomosis groups of Rhizoctonia solani to be associated with potatoes in the Pacific Northwest. Timothy Miles is now in a new position as a post-doctoral research plant pathologist at the USDA-ARS, U.S. Agricultural Research Station, Salinas, CA, working with Frank Martin on molecular detection technologies for Phytophthora species.

Imana Power, a native of Suriname in South America, is currently a Ph.D. student working with Albert Culbreath in the Department of Plant Pathology at The University of Georgia. She received her M.Sc. degree in ecological phytopathology from the Wageningen University and Research Center in The Netherlands. Imana's research is on characterizing resistance of peanut to $P$. arachidis, the causal agent of peanut rust, by determining levels of field resistance, components of resistance, and phenological resistance in newly developed breeding lines, by using rust resistance markers in rust-resistant peanut genotypes, and

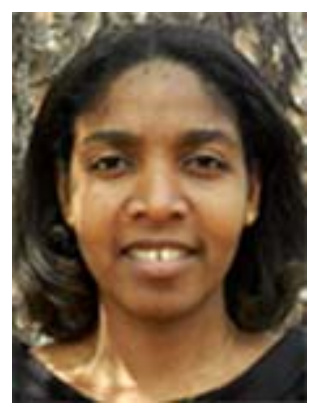
by assessing the genetic variability among $P$. arachidis populations. Her field studies have identified breeding lines with high levels of peanut rust resistance, of which several lines show multiple disease resistance under high disease pressure. In addition, preliminary results from the sequenced ITS region of geographically diverse $P$. arachidis isolates indicate highly homogeneous population structure of the pathogen. Imana received the 2013 R. J. Tarleton Student Fellowship Award and the 2013 K. E. Papa Award for Outstanding PhD Student from the Plant Pathology Department of UGA. After graduating, Imana plans to go back to her home country and contribute to strengthening agricultural research and education in Suriname. 


\section{Acknowledgments}

The sponsors of the 12th I. E. Melhus Graduate Student Symposium would like to thank the APS foundation and Raymond Martyn for providing the monetary awards to the four participants. Special thanks are extended to Michelle Bjerkness and Rhonda Wilkie from APS Headquarters for their support and help in making the 2012 symposium a great success. 